\title{
Yeni Kaliks[4]aren-içeren Polimerik Membranların Hazırlanması, Karakterizasyonu ve Uygulamaları
}

\author{
Mehmet Soner ENGIN ${ }^{1}$, Serkan SAYIN ${ }^{2}$, Seydahmet ÇAY ${ }^{3 *}$
}

\section{$\ddot{\mathbf{O z}}$}

$\mathrm{Bu}$ çalışmada, 5,17-bis-tert-butil-11,23-dikarboksilik asit-25,27-dihidroksi- 26,28-bis(3-tiyol-1-oksipropan)kaliks[4]aren (5) bileşiği başarıyla sentezlenmiş̧ir. Sentezlenen bileşiğin yapısı ${ }^{1} \mathrm{HNMR},{ }^{13} \mathrm{CNMR}$ ve elementel analiz teknikleri kullanılarak aydınlatılmıştır. Elde edilen merkapto grubu bağlı kaliks[4]aren türevi, yeni bir polimer içerikli membran hazırlanması için selüloz triasetat ve 2-nitrofenil oktil eter (o-NPOE) ile birlikte katkı malzemesi olarak kullanılmıştır. Kaliks[4]aren gömülü polimer içeren membranın (KPIM) yapısı ve yüzey morfolojisi, termogravimetrik analiz (TGA), taramalı elektron mikroskobu (SEM), Fourier dönüşümlü kızılötesi spektroskopisi (FT-IR) ve elemental analiz teknikleri kullanılarak belirlenmiştir. Ayrıca KPIM in $\mathrm{Zn}$ (II), $\mathrm{Pb}$ (II), $\mathrm{Co}(\mathrm{II}), \mathrm{Cd}$ (II), $\mathrm{Ni}$ (II) ve Cu (II) iyonlarının taşıma etkinliğini değerlendirmek için Donnan diyaliz sistemi kullanılmışıtır.

Anahtar Kelimeler: Kaliksaren, polimer içerikli membran (PIM), eser metaller, iyon taşınması, yüzey karakterizasyonu.

\section{Fabrication, Characterization, and Application of New Calix[4]arene-embeded Polymer Inclusion Membrane}

\begin{abstract}
In this study, the compound 5,17-bis-tert-butyl-11,23-dicarboxylic acid-25,27-dihydroxy-26,28-bis(3-thiol-1oxypropane)-calix[4]arene(5) successfully synthesized. The structure of the synthesized compound was characterized using ${ }^{1} \mathrm{HNMR},{ }^{13} \mathrm{CNMR}$ and elemental analysis techniques. The obtained mercapto group bound calyx[4]arene derivative was used as an additive together with cellulose triacetate and 2-nitrophenyl octyl ether (o-NPOE) for the preparation of a new polymer-containing membrane. The structure and surface morphology of the calyx[4]arene embedded polymeric membrane were determined using thermogravimetric analysis (TGA), scanning electron microscopy (SEM), Fourier transform infrared spectroscopy (FT-IR) and elemental analysis techniques. In addition, Donnan dialysis system was used to evaluate the transport efficiency of $\mathrm{Zn}$ (II), $\mathrm{Pb}$ (II), $\mathrm{Co}(\mathrm{II}), \mathrm{Cd}$ (II), $\mathrm{Ni}$ (II) and $\mathrm{Cu}$ (II) ions in KPIM.
\end{abstract}

Keywords: Calixarene, polymer inclusion membrane (PIM), trace metals, ion transportation, surface characterization.

\footnotetext{
${ }^{1}$ Giresun University, Faculty of Engineering, Department of Food Engineering, Giresun, Turkey, soner.engin@giresun.edu.tr

${ }^{2,3}$ Giresun University, Faculty of Engineering, Department of Environmental Engineering, Giresun, Turkey,

serkan.sayin@giresun.edu.tr seydahmet.cay@giresun.edu.tr
} 


\section{Giriş}

Son y1llarda membran teknolojisi, diğer klasik analitik metotlara (kimyasal çöktürme, adsorpsiyon vb.) göre ekonomik olması ve uygulamadaki kolaylığı bakımından ayırma işlemlerinde oldukça fazla tercih edilmektedir. Membran teknolojisinde çok çeşitli formlara sahip membranlar (Nagarale ve ark., 2006) bulunmakta olup bunlar arasında ayırma işlemlerinde en çok iyon değiştirici özelliğe sahip polimer yapılı membranlar kullanılmaktadır. Bu nedenle, yeni ve farklı formlardaki membranlara sürekli ihtiyaç duyulmaktadır. $\mathrm{Bu}$ membranlar, yüksek kararlılık ve seçicilikleri nedeniyle sürekli gelişerek daha fazla kullanım alanı bulmuştur. Özellikle polimerik membranlar; mikrofiltrasyon, ultrafiltrasyon, nanofiltrasyon ve ters osmoz gibi endüstriyel uygulamalarda geniş bir kullanım alanına sahiptir. Bu membranların hazırlanmasında Polieter sülfon (PES), Polivinil alkol (PVA), Polivinil prolidon (PVP), Polisülfon (PS), Poliviniliden florür (PVDF) gibi polimerler yüksek kararlılık, termal, kimyasal ve mekaniksel direnç gibi özelliklerinden dolayı yaygın olarak kullanılmaktadır (Sellami ve ark. 2021). Polimer içerikli membranlar; uzun süre kararlılık, taşınımın daha hızlı olması ve kolay hazırlanabilme gibi avantajlara sahip olmasından dolayı metal iyon taşınımında ilgi görmektedir. Polimer içerikli membranlar, bir polimer destek maddesi ve membran içinde metal iyonlarının sorpsiyonunu sağlayan bir organik taşıyıcıdan oluşmaktadır. Taç eterler (Nazarenko ve ark. 1997), amitler (Kim ve ark. 2001), fosfonatlar (Lamb ve Nazarenko, 1997), kaliksarenler (Kim ve ark. 2001; Levitskaia ve ark. 2000, Engin ve ark. 2017; 2018) gibi birçok organik taşıyıcı metal iyonlarının sorpsiyonu için kullanılmaktadır.

Polimer içerikli membranların önemli özelliklerinden birisi de taşınım etkisini belirleyen polimer matriksinde organik taşıyıcının dağılımıdır. Membranın kalınlığı boyunca metal iyonları ve organik taşıyıcının dağılımının belirlenmesi membranın kalitesi hakkında önemli bilgiler sağlayacaktır. Donnan diyaliz, membranların kullanıldığı ve konsantrasyon farkı ile iyonların taşınmasının gerçekleştirildiği bir ayırma prosesidir (Ho ve Sirkar, 1992).

Son kırk yıldır membranlar endüstriyel ayırma teknolojisi alanında önemli bir araştırma konusu olmuştur. Membran teknolojisinin kullanımındaki artış membran gelişiminde çok önemli ilerlemeler, geleneksel ayırma süreçlerine tercihen teknolojinin daha geniş kabul görmesi, çevre bilinci ve en önemlisi sıkı çevre düzenlemeleri ve mevzuat ile sürmüştür. Çeşitli membran prosesleri şu anda kimya (petrokimya gibi), ilaç, gıda ve içecek sanayide uygulamaları mevcuttur. Özellikle membran teknolojisinin güçlenmesi ve büyümesi içme suyunun üretimi ve atık suyun saflaştırılmasında gözlenmektedir (Hofman ve Pietrzak, 2013)

Ağır metallerle kirlenmiş su ciddi bir çevre sorunu haline gelmiştir. Ağır metaller günlük hayatta çeşitli kaynaklardan boşaltılır ve su içinde çözüldüğünde kolayca iyonlarına oksitlenebilir (Hofman ve Pietrzak, 2013). Ağır metalller arasında kadmiyum (Cd), kurşun (Pb), civa (Hg), nikel 
(Ni), bakır $(\mathrm{Cu})$ ve çinko $(\mathrm{Zn})$ en tehlikelileridir. Bugüne kadar sulardan metal iyonlarının uzaklaştırılmasında genellikle üç ana metot kullanılmaktadır. Bunlar kimyasal çöktürme, ters osmoz ve aktif karbon ya da iyon değiştirici reçinelerle yapılan adsorpsiyon prosesleridir. Bu metotlar metal iyonlarının uzaklaştırılmasında etkili olmalarına rağmen uygulanmalarının pahalı olması, tekrar kullanılamaması ya da membran kirliliğine sebep olması gibi dezavantajlara sahiptirler (Hofman ve Pietrzak, 2013).

Yüksek seçiciliğe sahip membranlar için yeni organik moleküllerin dizaynı hala büyük bir öneme sahiptir. Literatürdeki birçok membran seçicilik yönünden yükssek verimli değildir. Kaliks[n]aren katkısı membranların duyarlılığını ve seçiciliğini artırmıştır (El-Sayed, 2013). İyonofor olarak yeni sentezlenen kaliks[n]aren bileşiği, titanyum seçici olarak çalışmalarda kullanılmıştır (Chester ve ark. 2014). Ayrıca farklı kaliks[n]aren bileşikleri elektrokimyasal olarak elektrotlarda kullanılmış ve $\mathrm{Hg}^{2+}, \mathrm{Ni}^{2+}$ gibi katyonlara karşı seçicilik göstermiştir (Ebdelli ve ark. 2011). $\mathrm{Pb}^{2+}$ metaline karşı seçici olan kaliksaren türevleri ile ilgili yapılmış güncel çalışmalar literatürde mevcuttur (Konczyk ve ark. 2021)

$\mathrm{Bu}$ çalışma kapsamında 5,17-bis-ter-butil-11,23-dikarboksilik asit-25,27-dihidroksi- 26,28bis(3-tiyol-1-oksipropan)-kaliks[4]aren (5) sentezlenerek, yapısı spektroskopik ve diğer teknikler kullanılarak aydınlatılmıştır. Sentezlenen bileşik ilk kez polimer bazlı membranların hazırlanmasında etkin reseptörler olarak kullanılmıştır. Hazırlanan kaliksaren-modifiye polimer esaslı membranın (KPİM) karakterizasyonu da farklı teknikler kullanılarak yapılmıştır. Hazırlanan yeni KPİM, sulu çözeltileri Zn (II), Pb (II), Co(II), Cd (II), Ni (II) ve Cu (II) iyonlarının uzaklaştırılmasında kullanılmıştır.

\section{Materyal ve Metot}

\subsection{Enstrümental Teknikler}

Erime noktası Gallenkamp marka erime noktası tayin cihazı ile yapılmıştır. NMR spektrumları Bruker Avance III $400 \mathrm{MHz}$ spectrofotometre ile alınmış ve standart olarak TMS kullanılmıştır. NMR spektrumunda kimyasal kayma değerleri ppm cinsinden belirtilmiştir. FT-IR spektrumları Jasco FT/IR-6600 spektrofotometresinden alınmıştır. Element analiz sonuçları Costech ECS 4010 analiz cihazından alınmıştır. İz metalleri analizinde Bruker 820-MS marka ICP-MS ve Hach HDR400 marka UV-Vis Spektrofotometresi kullanılmıştır. Membran görüntüleri Hitachi SU 1510 cihazı ile alınmıştır. Termogravimetrik analiz Seteram İnstrumentation Labsys Evo marka cihaz ile yapılmıştır. Analitik TLC'ler silika jel tabakasıyla $\left(\mathrm{SiO}_{2}\right.$, Merck $\left.60 \quad \mathrm{~F}_{254}\right)$ kaplanmış alüminyum plakalar kullanarak yapılmıştır. NaH, \%80’lik parafinli olarak kullanılmıştır. Tetrahidrofuran ve toluen (BDH) 
sodyum/benzofenon üzerinden refluks edilerek kurutulup daha sonra fraksiyonlu distilasyonla distillenip kullanılmıştır. $\mathrm{CH}_{2} \mathrm{Cl}_{2}, \mathrm{CaCl}_{2}$ 'den ve $\mathrm{MeOH}, \mathrm{Mg}$ üzerinden distillenip kullanılmıştır. Tüm çözeltiler, saf su (Millipore Milli-Q Plus) ile hazırlanmıştır.

\subsection{Polimerik membranlarının hazırlanması ve karakterizasyonu}

Polimer inklüzyon membran (PİM) yöntemi kullanılarak membranlar elde edilmiştir. $\mathrm{Bu}$ amaçla, refrerans membran olarak, 0,2 g CTA $10 \mathrm{~mL} \mathrm{CHCl}_{3}$ de çözülmüş, üzerine 0,3 mL 2-NPOE ve $3 \mathrm{~mL}$ DMF eklenmiş, son olarak petriye dökülerek $140 \mu \mathrm{m}$ kalınlıkta membran elde edilmiştir. Taşıyıcı içeren membran ise; birinci beherde $10 \mathrm{mg}$ 5,17-Dinitro-25,27-bis (3-tiyol-1-oksipropan)26,28-dihidroksikaliks[4]aren, $5 \mathrm{~mL}$ DMF de çözülmüş, ikinci beherde ise $0,2 \mathrm{~g} \mathrm{CTA}, 10 \mathrm{~mL} \mathrm{CHCl}_{3}$ de çözülerek, iki beher karıştırılmış ve son olarak karışıma 0,3 mL 2-NPOE eklenmiştir. Karışım bir petriye dökülerek, çözücülerin uçurulması sağlanmış, elde edilen membran kalınlığı $143 \mu$ m olarak ölçülmüştür. Deneylerde kullanılan donnan diyaliz hücreleri Şekil 1 de gösterilmiştir.

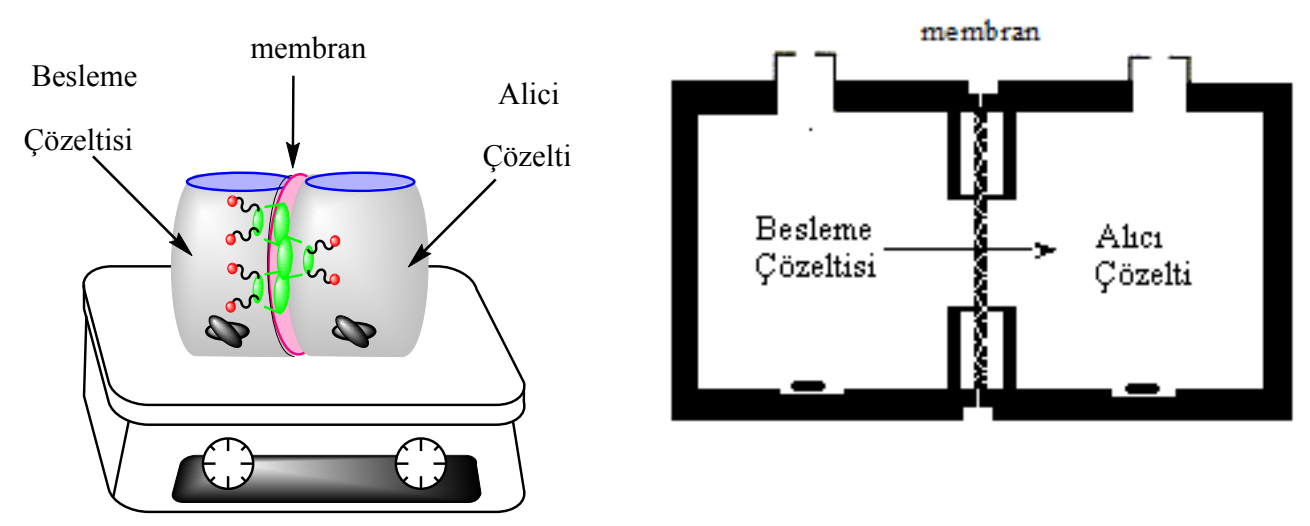

Şekil 1. Donnan diyaliz hücreleri

Kaliks[4]aren içerikli polimer içeren membranın yapısı ve yüzey morfolojisi, termogravimetrik analiz (TGA), taramalı elektron mikroskobu (SEM), Fourier dönüşümlü kızılötesi spektroskopisi (FT-IR) ve elemental analiz teknikleri kullanılarak belirlenmiştir.

\subsection{Metal taşınım çalışmaları}

Metal iyonlarının sulu bir çözelti taşınımı, teflon'dan yapılmış iki ayrılabilir bölümden oluşan Şekil 1 de gösterilen hücreler kullanılarak gerçekleştirilmiştir. $7 \mathrm{~cm}^{2}$ lik bir yüzey alanına sahip olan membran, 40 mL'lik iki hücre arasına sıkıştırılmıştır. Deney sırasında her iki faz da manyetik bir karıştırıcı ile $500 \mathrm{rpm}$ 'de karıştırılmıştır. Tüm ölçümler $24^{\circ} \mathrm{C}^{\prime}$ de gerçekleştirilmiştir. Besleme fazı, 
$10^{-5} \mathrm{~mol} / \mathrm{L}$ eser metal iyonu ve alıcı faz, deiyonize su içermektedir. Çözeltinin $(1 \mathrm{~mL})$ örneklenmesi düzenli aralıklarla (her 2 saatte bir) gerçekleştirilmiş ve membrandan iletilen eser metal iyonları Bruker 820-MS marka ICP-MS kullanılarak ölçülmüştür.

\section{Bulgular ve Tartışma}

\subsection{Sentezler}

1-5 arasındaki bileşikler, literatürde yer alan prosedürlere göre sentezlenmiştir (Gutsche ve ark. 1988, Li ve ark. 1999, Demirkol ve ark. 2014, Gokoglan ve ark. 2015).

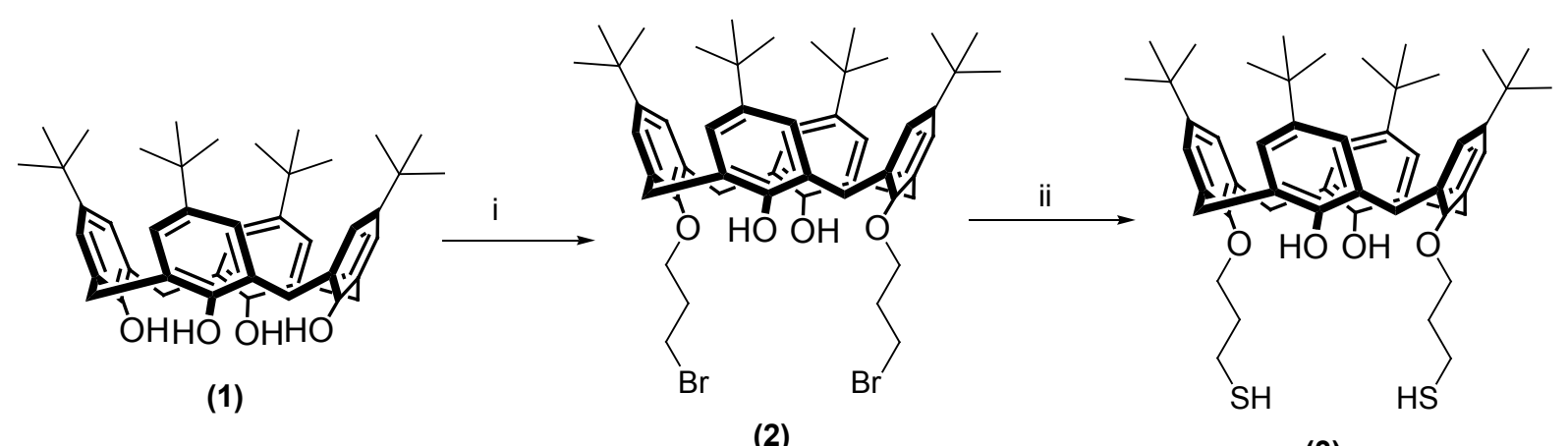

(2)

(3)

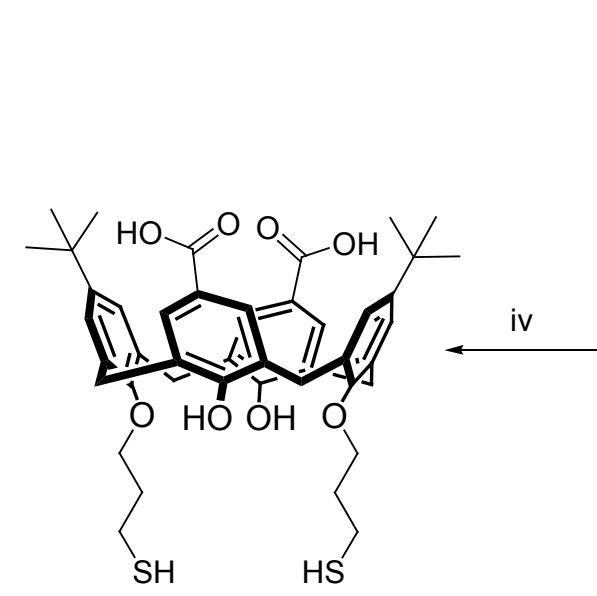

(5)

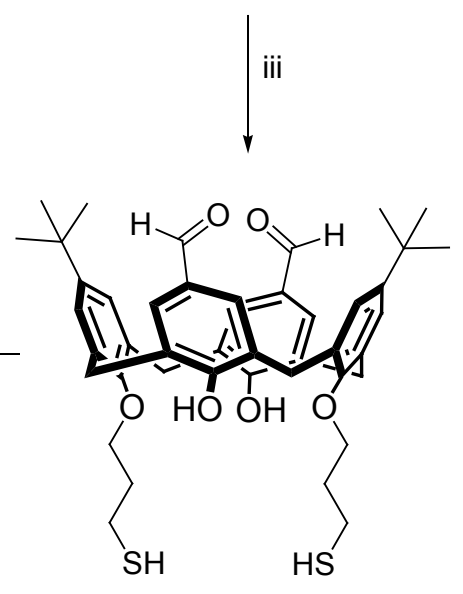

(4)

Şekil 2. 5,17-bis-tert-butyl-11,23-dicarboxylic acid-25,27-dihydroxy- 26,28-bis(3-thiol-1-oxypropane)kaliks[4]arenin (5) sentezi için. Reaksiyon şartları: (i) $\mathrm{K}_{2} \mathrm{CO}_{3}, \mathrm{CH}_{3} \mathrm{CN}, 1$,3-dibrompropan; (ii) thiourea, $\mathrm{KOH}, \mathrm{CH}_{3} \mathrm{CN}$; (iii) TFA, hekzametilentetramin; (iv) sülfamik asit, sodium klorit, $\mathrm{CHCl}_{3} /$ aseton. 


\subsection{KPIM in karakterizasyonu}

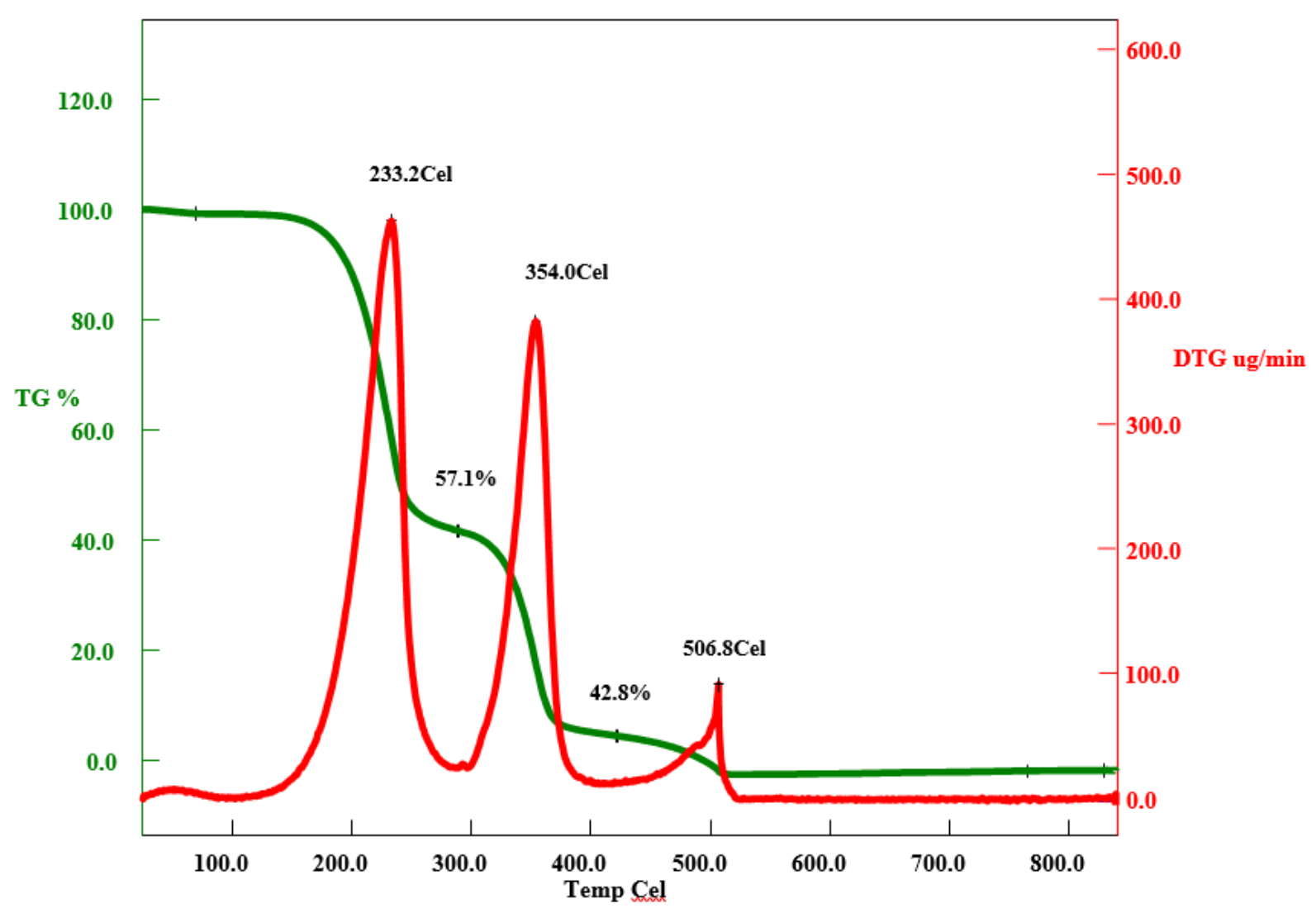

Şekil 3. KPIMM' in TGA Termogramı

Şekil 3'te görüldüğü gibi kaliks[4]arenin immobilize olduğu selüloz triasetat-bazlı membranların TGA termogramlarında sirasıyla $150-570{ }^{\circ} \mathrm{C}$ sıcaklık aralığında toplam \%100 ve 130$527{ }^{\circ} \mathrm{C}$ sıcaklık aralığında toplam \%99.9 luk bir kütle kaybı görülmektedir. Burada gözlenen yüzde kütle kayıpları kaliksaren molekülleri ve membrandaki polimerik gruba ait olduğu söylenebilir.

Kaliksaren içermeyen selüloz triasetat-bazlı membran ve KPIM'in FT-IR spekrumuna baktığımızda genel olarak membranlardaki organik polimerlerin intensitesinin kaliksaren bileşiklerinden fazla olmasından dolayı kaliksarenin karakteristik pikleri perdelenmiştir. 

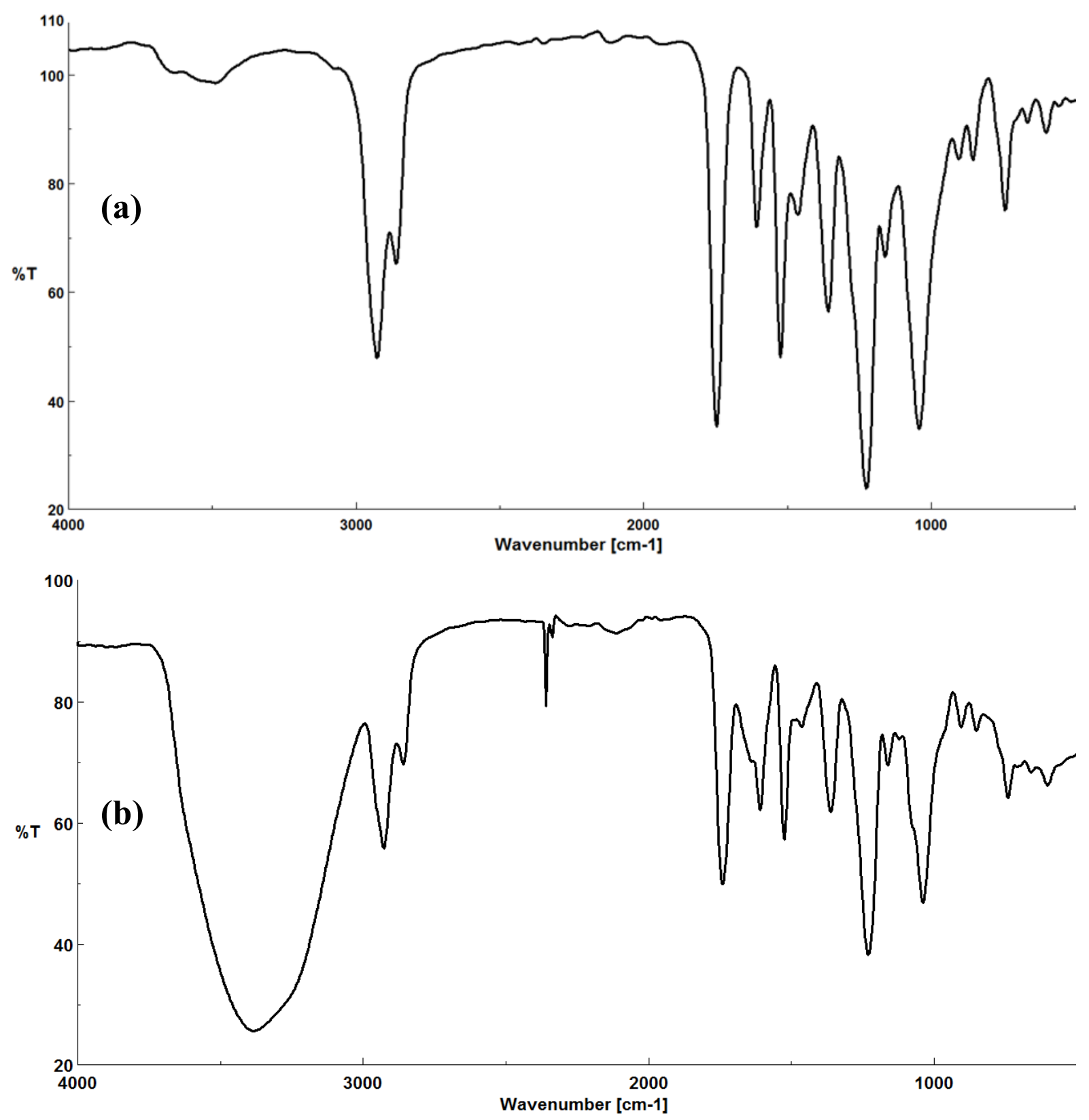

Şekil 4. Kaliksaren içermeyen (a) ve içeren (b) membranların FT-IR grafikleri

KPİM ve kaliksaren içermeyen polimer inklüzyon membranının morfolojisi, Şekil 5 te görüldüğü gibi taramalı elektron mikroskobu (SEM) ile değerlendirilmiştir. Şekil 5-b'de gösterildiği gibi, KPİM, yüzey üzerindeki şekli ve dağılımı ile ilgili olarak önemli ölçüde farklı morfoloji sergilemiştir. Bu bulgular, kaliks[4]arenin polimer inklüzyon membranı üzerine başarılı bir şekilde gömüldüğünü göstermiştir. 

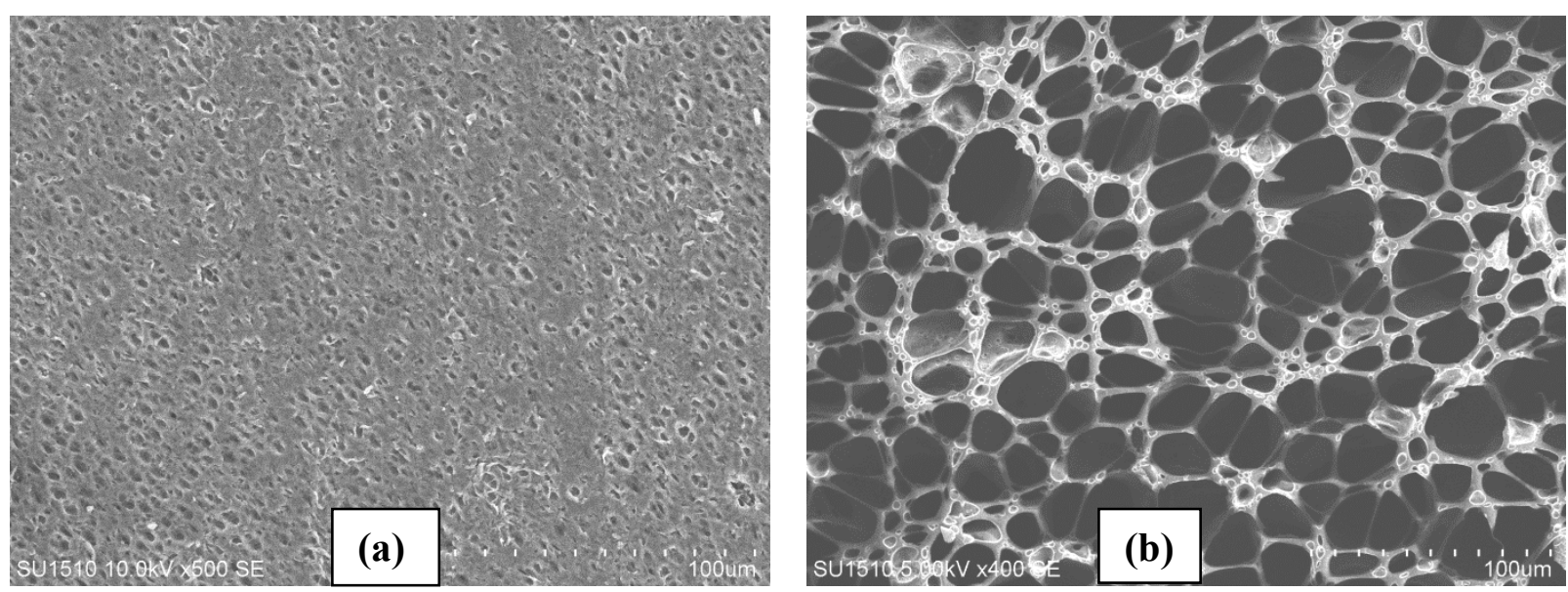

Şekil 5. Kaliksaren içermeyen membran (a), KPİM (b) SEM görüntüleri

KPİM içerine gömülmüş 5,17-bis-ter-butil-11,23-dikarboksilik asit-25,27-dihidroksi- 26,28bis(3-tiyol-1-oksipropan)-kaliks[4]aren (5) sentezlenerek miktarını değerlendirmek için element analizi tekniğgi uygulanmıştır. Tablo 1 de olduğu gibi merkapto içerikli kaliks[4]aren türevinin kükürt içeriği ile ilgili sonuç; KPİM 'in $1 \mathrm{~g}$ destek tabakasında 4,18 mmol kalisaren içeriğine karşılık gelen \% 6,69 kükürt miktarını içerdiğini göstermiştir.

Tablo 1. Kaliksaren içermeyen membran ve KPİM elementel analiz sonuçları

\begin{tabular}{lccccc}
\hline & $\mathrm{C}(\%)$ & $\mathrm{H}(\%)$ & $\mathrm{S}(\%)$ & $\mathrm{N}(\%)$ & $\begin{array}{c}\text { Membrana gömülen kalisaren } \\
\text { miktarı (mmol/g) }\end{array}$ \\
\hline Kör & 62.07 & 7.40 & - & 3.86 & - \\
\hline KPİM & 71.71 & 5.27 & 6.69 & 0.67 & $\sim 4.18$ \\
\hline
\end{tabular}

\subsection{Metal taşınım çalışmaları}

Eser metallerin akış değerleri, ilk faz tekniğinin zaman profilinden ve alıcı faz konsantrasyonundan hesaplanmış ve sonuçlar Tablo 2'de verilmiştir. Sonuçlar \%95 güven seviyesinde ( $\mathrm{N}=3$ ) elde edilmiştir. Ni (II), $\mathrm{Pb}$ (II), $\mathrm{Zn}$ (II), Cu (II), Cd (II) ve Co (II) RF değerleri de Tablo 2'de gösterilmiştir. KPİM için maksimum geri kazanma değeri 4. Günde gerçekleşmiş olup, metal iyonları için ortalama olarak birbirine yakın verim olduğu gözlenmiştir. 
Tablo 2. KPIM için farklı iyonların RF ve akış değerleri

\begin{tabular}{llc}
\hline İyon & $\mathbf{J x 1 0}^{\mathbf{1 5}}\left(\mathbf{m o l} \cdot \mathbf{c m}^{-\mathbf{2}} \mathbf{.}^{\mathbf{- 1}}\right)$ & RF değerleri (4. gün) \\
\hline $\mathrm{Pb}(\mathrm{II})$ & $512,00( \pm 0,01)$ & 41,6838 \\
$\mathrm{Zn}(\mathrm{II})$ & $379,00( \pm 0,01)$ & 40,3578 \\
$\mathrm{Cu}(\mathrm{II})$ & $428,00( \pm 0,01)$ & 43,3265 \\
$\mathrm{Ni}(\mathrm{II})$ & $489,00( \pm 0,01)$ & 41,3502 \\
$\mathrm{Cd}(\mathrm{II})$ & $119,00( \pm 0,01)$ & 6,4718 \\
$\mathrm{Co}(\mathrm{II})$ & $338,00( \pm 0,01)$ & 24,0664 \\
\hline
\end{tabular}

\section{Sonuçlar ve Öneriler}

Ağır metallerin çevreye ve dolayısıyla insan sağlığına vermiş olduğu zararlar nedeniyle seçimli olarak ortamdan uzaklaştırılması günümüzde oldukça önem kazanmıştır. Bu amaçla gerçekleştirilen polimer içerikli membran çalışmalarımızda, kaliksaren birimleri (KPİM) taşıan yeni bir polimer inklüzyon membranı üretilmiş ve yapısı spektroskopik ve diğer teknikler kullanılarak karakterize edilmiştir. KPİM'in $\mathrm{Ni}$ (II), Pb (II), Zn (II), Cu (II), Cd (II) ve Co (II) 'ye karşı katyon taşıma etkinliğini değerlendirmek için Donnan diyaliz yöntemi uygulanmış ve sonuçlar aşağıdaki gibi özetlenmiştir:

1) SEM görüntüleri, kaliksaren türevinin membrana başarıyla gömüldügüünü göstermiştir.

2) Donnan diyaliz hücresinde, KPİM kullanılarak sulu çözeltiden metal iyonlarının taşınması ile ilgili akış değerleri ve RF değerleri hesaplanmıştır.

3) Taşıma deneyleri 4 günlük periyotlarla yedi kez aynı membran kullanılarak yapılmıştır. Çalışma sayısının metal iyonlarının taşınmasını azalttı̆̆ı gözlenmiştir.

4) Donnan diyaliz yönteminin sulu çözeltiden altı metal iyonunun uzaklaştırılmasında KPİM ile uygulanabilir bir yöntem olduğu sonucuna varılmıştır.

\section{Teșekkür}

$\mathrm{Bu}$ çalışmaya maddi destek veren Türkiye Bilimsel ve Teknolojik Araştırma Kurumu'na (TÜBİTAK Hibe Numarası 215Z570) teşekkür ederiz.

\section{Yazarların Katkısı}

Tüm yazarlar çalışmaya eşit katkıda bulunmuştur. 


\section{Çıkar Çatışması Beyanı}

Yazarlar arasında herhangi bir çıkar çatışması bulunmamaktadır.

\section{Araştırma ve Yayın Etiği Beyanı}

Yapılan çalışmada araştırma ve yayın etiğine uyulmuştur.

\section{Kaynaklar}

Chester, R., Sohail, M., Ogden, M.I., Mocerino, M., Pretsch, E., De Marco, R. 2014. “A calixarene-based ionselective electrode for thallium(I) detection". Analytica Chimica Acta. 851, 78-86.

Demırkol, D.O., Yildiz, H.B., Sayin, S., Yilmaz, M. 2014. Enzyme immobilization in biosensor constructions: self-assembled monolayers of calixarenes containing thiols. RSC Advances. 4 , 19900-19907.

Ebdelli, R., Rouis, A., Mlika R., Bonnamour, I., Jaffrezic-Renault, N., Ben Ouada, H., Davenas, J. 2011. Electrochemical impedance detection of $\mathrm{Hg}^{2+}, \mathrm{Ni}^{2+}$ and $\mathrm{Eu}^{3+}$ ions by a new azo-calix[4]arene membrane. Journal of Electroanalytical Chemistry. 661,31-38.

El-Sayed, M. A.2013. The use of calixarene as ionophores in potentiometric ion-selective electrodes of naftidrofuryl oxalate using microsized membrane sensors for kinetic study of naftidrofuryl (NFT) degradation. European Journal of Chemistry, 4 (2) ,124-131.

Engin M.S., Cay S., Sayin S., Eymur S., Sardohan Koseoglu T. 2017. Preparation of calix [4] arene-embedded polysulphone membranes, and utilisation of its Cr (VI) transport efficiency. Supramolecular Chemistry. 29(6)455-461.

Engin M.S., Cay S., Sayin S., 2018. Utilization of transport efficacy of novel calix [4] arene-embedded polymer inclusion membrane towards trace metals. Journal of Inclusion Phenomena and Macrocyclic Chemistry. 92(1) 173-179.

Gokoglan, T.C., Soylemez, S., Kesik, M., Unay, H., Sayin, S., Yildiz, H.B., Cirpan, A., Toppare, L. 2015. A novel architecture based on a conducting polymer and calixarene derivative: its synthesis and biosensor construction. RSC Advances. 5, 35940-35947.

Ho, W.S.H. ve Sirkar, K.K. 1992 "Dialysis, in Membrane Handbook, Part IV; Van Nostrand Reinhold" New York, 161-215

Hofman, M. ve Pietrzak, R.2013. Copper ions removal from liquid phase by polyethersulfone (PES) membranes functionalized by introduction of carbonaceous materials. Chemical Engineeing Journal, 215-216, 216-221.

Gutsche C.D ve Nam K.C. 1988. Calixarenes 22. Synthesis, Properties, and Metal Complexation of Aminocalixarenes. Journal of the American Chemical Society 110(18): 6153-62.

Kim, J.S., Yu,S.H., Cho,M.H., Shon,O.J., Rim,J.A., Yang,S.H., Lee,J.K., Lee,S.J. 2001. Preparation and IonBinding Properties of Calix[4]crown-Containing Polyesters. Bulletin of the Korean Chemical Society. 22, 519 .

Konczyk, J, ve Ciesielski, W. 2021 Calixresorcin[4]arene Mediated Transport of Pb(II) Ions through Polymer Inclusion Membrane. Membranes 11 (4), 285.

Lamb,J.D. ve Nazarenko, A.Y.1997. Lead(II) ion sorption and transport using polymer inclusion membranes containing tri-octylphosphine oxide. Journal of Membrane Science. 134, 255.

Levitskaia,T.G., Macdonald,D., Lamb,J., Moyer,B.2000. Prediction of the carrier-mediated cation flux through polymer inclusion membranes via fundamental thermodynamic quantities: complexation study 
of bis(dodecyloxy)calix[4]arene-crown-6 with alkali metal cations. Physical Chemistry Chemical Physics. 7,1481.

Li, Z.-T.; Ji, G.-Z.; Zhao, C.-X.; Yuan, S.-D.; Ding, H.; Huang, C.; Du, A.-L.; Wei, M. 1999. Self-assembling calix[4]arene [2]catenanes. Preorganization, conformation, selectivity, and efficiency. Journal of Organic Chemistry. 64, 3572-3584.

Nagarale, R.K., Gohil, G.S., Shahi,V.K. 2006. Recent developments on ion-exchange membranes and electromembrane processes. Advances in Colloid and Interface Science, 119, 97-130.

Nazarenko,A.Y. ve Lamb,J.D. 1997. Selective metal ion sorption and transport using polymer inclusion membranes containing dicyclohexano-18-crown-6. Separation Science and Technology, 32, 2749-2764.

Sellami, F, Kebiche-Senhadji, O, Marais, S, Colasse, L, Fatyeyeva, K, 2020. Enhanced removal of Cr(VI) by polymer inclusion membrane based on poly (vinylidene fluoride) and Aliquat 336. Separation and Purification Technology, 248, 117038. 